\title{
Letter to Editor: The Prevalence of Hyperamylasemia and Its Relationship With Mortality in COVID-19 Patients
}

\author{
Zahra Ataee $^{1}$ Q, Maliheh Ziaee ${ }^{2}$, Atieh Yaghoubi ${ }^{3,4}$, Leila Ataei ${ }^{3,4}$, Saman Solemanpour ${ }^{3,4^{*}}$ Q \\ 1.Department of Internal Medicine, School of Medicine, Mashhad University of Medical Sciences, Mashhad, Iran \\ 2.Department of Community Medicine, School of Medicine, Social Determinants of Health Research Center, Gonabad University of Medical Sci- \\ ences, Gonabad, Iran. \\ 3. Antimicrobial Resistance Research Center, Bu-Ali Research Institute, Mashhad University of Medical Sciences, Mashhad, Iran. \\ 4. Department of Microbiology and Virology, Faculty of Medicine, Mashhad University of Medical Sciences, Mashhad, Iran.
}

\begin{tabular}{|c|c|}
\hline $\begin{array}{l}\text { Use your device to scan } \\
\text { and read the article online }\end{array}$ & $\begin{array}{l}\text { Citation: Ataei Z, Ziaei M, Yaghoubi A, Ataei L, Solemanpour S. The Prevalence of Hyperamylasemia and Its Relationship } \\
\text { With Mortality in COVID-19 Patients. International Journal of Medical Toxicology and Forensic Medicine. 2021; 11(3):?-?. } \\
\text { https://doi.org/10.32598/ijmtfm.v11i3.33813 }\end{array}$ \\
\hline 0 & d tol"https://doi.org/10.32598/ijmtfm.v11i3.33813 \\
\hline
\end{tabular}

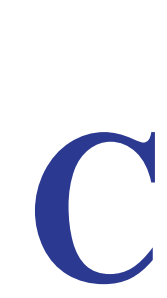

\section{Letter to Editor}

oronavirus Disease 2019 (COVID-19)

is an infectious disease. This condition is caused by Severe Acute Respiratory Syndrome Coronavirus (SARS-CoV). SARS-CoV-2 affects different individuals in multiple ways; it commonly represents pulmonary symptoms, such as fever, dry cough, sore throat, aches and pains, headache, as well as fatigue [1]. However, extra-pulmonary symptoms caused by COVID-19 attracted much attention. SARS-CoV-2, in addition to the respiratory tract, affects the gastrointestinal tract with symptoms, including nausea or vomiting $(7.8 \%)$, diarrhea (7.7\%), and abdominal pain (2.7\%) [2]. Furthermore, lymphopenia, coagulation disorders, the higher level of the liver enzymes, LDH (Lactate Dehydrogenase), CRP, D-dimer, and amylase were observed in severe acute COVID-19 patients [2]. Acute Pancreatitis (AP) is the most prevalent gastrointestinal cause of the hospital admission of COVID-19 patients [3, 4].

Acute pancreatitis is defined with some prevalent symptoms, including typical abdominal pain, serum amylase and lipase activity of at least 3 times $>$ ULN, characteristic findings of acute pancreatitis on contrastenhanced Computed Tomography (CT), and less commonly, Magnetic Resonance Imaging (MRI), or transabdominal ultrasonography [5]. According to the reports, pancreas-specific plasma amylase was increased in COVID-19 patients with acute pancreatitis [3, 4]. However, the increase in amylase is not specific to acute pancreatitis. Approximately $11 \%-13 \%$ of patients with nonpancreatic abdominal pain have increased amylase; also, a high level of amylase was observed in $60 \%$ of HIV patients [6]. Increasing the level of plasma amylase is due to the enhanced production of this enzyme from different sources (pancreas, salivary glands, \& lungs) and declined clearance of amylase $[7,8]$.

This research aimed to investigate the prevalence of hyperamylasemia in patients with respiratory distress syndrome caused by COVID-19 in patients admitted in the adult wards of Imam Reza Hospital and its relationship with mortality. This was a cross-sectional study on 128 patients with COVID-19 who were admitted to the COVID-19 wards of Imam Reza Hospital in Mashhad City, Iran, in March 2020 (IR.MUMS.REC.1399.193). Imam Reza Hospital is a referral center for COVID-19 patients who are admitted to a 610-bed hospital. The

\section{* Corresponding Author:}

Saman Soleimanpour, PhD.

Address: Antimicrobial Resistance Research Center, Bu-Ali Research Institute; Department of Microbiology and Virology, Faculty of Medicine, Mashhad University of Medical Sciences, Mashhad, Iran.

Tel: +98 (912) 6590092

E-mail:soleimanpours@mums.ac.ir 
normal range for adults for amylase in a blood sample is $80 \mathrm{U} / \mathrm{L}$. All patients were aged $\geq 16$ years with a positive test for SARS-CoV-2. Patients under 16 years were excluded from this study. The written informed consent and questionnaire form was completed for each subject to access demographic data and clinical information. Moreover, the amylase blood test was measured for all individuals. Descriptive statistics were used to analyze the obtained data. Besides, the Chi-squared test was used to compare the qualitative data. SPSS was used for data analysis at the significance level of $\mathrm{P}<0.05$. A total of 128 Reverse Transcriptase-Polymerase Chain Reaction (RT-PCR) confirmed COVID-19 patients were admitted to the COVID-19 wards at Imam Reza Hospital in Mashhad City, Iran. The analysis was restricted to 128 patients, including 60 males (46.9) and 68 females (53.1), aged $\geq 16$ years. As of March 6, 106(82.8\%) patients were discharged and 22(17.2\%) cases were expired. A high amylase level was observed in $82.8 \%$ of the discharged subjects and $17.2 \%$ of the deceased subjects. The total Odds Ratio (OR) for amylase was $2.321(95 \% \mathrm{CI}=0.903-5.965)$, amylase level in discharge patients $(\mathrm{OR}=1.176,95 \% \mathrm{CI}=0.957-1.446)$, and death $(\mathrm{OR}=0.507,95 \% \mathrm{CI}=0.240-1.071)$. The present study suggested that hyperamylasemia is prevalent in the $\mathrm{CO}$ VID-19 admitted patients $(\mathrm{OR}=2.321,95 \% \mathrm{CI}=0.903$ 5.965); however, amylase levels were not significantly associated with death $(\mathrm{OR}=0.507,95 \% \mathrm{CI}=0.240-1.071)$. A study was conducted on 52 patients with COVID-19 who were admitted to the Zhongnan Hospital affiliated with Wuhan University, China. They investigated the incidence of pancreatic injury through the assessment of the blood levels of amylase and lipase. The obtained data revealed a $17 \%$ incidence of pancreatic injury among 52 patients with COVID-19 pneumonia. Moreover, this study suggested a mild increase in the blood levels of pancreatic enzymes (mean \pm SD serum amylase: $115 \pm 25$ U/L; serum lipase: $71 \pm 34 \mathrm{U} / \mathrm{L}$ ). However, none of these patients presented abdominal pain or clinically severe pancreatitis [9]. Another study reported a 17\% incidence of pancreatic injury among the 67 severe COVID-19 patients; this injury was observed in the $7.46 \%$ of CT scan results. They were mainly manifested as focal pancreatic enlargement or pancreatic ductal dilatation. The collected results suggested that the incidence of pancreatic injury in patients with mild disease was low (1.85\%). Abdominal pain or pancreatic necrosis was not observed in these patients [10]. Evidence suggested that several factors can cause acute pancreatitides, such as pancreatic autodigestion, enzyme activation, complement system activation, microcirculation disturbance theory, leukocyte excessive activation, as well as pancreatic acinar cell apoptosis and necrosis. Viral pancreatitis occurs following the direct injury of pancreatic acinar cells via inflammation and edema [11]. Moreover, the injury of pancreatic acinar cells caused by the virus can result in leaking intracellular enzymes or precipitates a process of cell death. Angiotensin-Converting Enzyme 2 (ACE2) is well known as an entry receptor of SARS-CoV-2; it is overexpressed in the gastrointestinal epithelium of infected host as well as pancreatic islets that can lead to acute inflammation and even in some cases caused acute diabetes $[12,13]$. Therefore, measuring lipase or amylase in COVID-19 patients, especially in patients who have abdominal pain is of importance. The present study failed to assess the serum level of amylase. In addition, we had no possible imaging therapy to reject or confirm the presence of pancreatitis. Therefore, for future studies, we suggest using imaging therapy as well as evaluating the serum level of amylase in these patients.

\section{Ethical Considerations}

\section{Compliance with ethical guidelines}

All ethical principles were considered in this article (IR.MUMS.REC.1399.193).

\section{Funding}

This study was funded by the Mashhad University of Medical Sciences (MUMS).

\section{Author's contributions}

All authors equally contributed to preparing this article.

\section{Conflict of interest}

The authors declared no conflicts of interest.

\section{Acknowledgments}

The authors regret the omission of many colleagues' research articles because of space constraints.

\section{References}

[1] Tanno LK, Casale T, Demoly P. Coronavirus disease (COVID)-19: World Health Organization definitions and coding to support the allergy community and health professionals. J Allergy Clin Immunol Pract. 2020; 8(7):2144-8. [DOI:10.1016/j. jaip.2020.05.002] [PMID] [PMCID] 
[2] Sultan S, Altayar O, Siddique SM, Davitkov P, Feuerstein JD, Lim JK, et al. AGA institute rapid review of the GI and liver manifestations of COVID-19, meta-analysis of international data, and recommendations for the consultative management of patients with COVID-19. Gastroenterology. 2020; 159(1):32034.e27. [DOI:10.1053/j.gastro.2020.05.001] [PMID] [PMCID]

[3] Gupta V. COVID-19 and Acute Pancreatitis: What do surgeons need to know? Indian J Surg. 2020; 82(3):301-4. [DOI:10.1007/s12262-020-02447-w] [PMID] [PMCID]

[4] Hadi A, Werge MP, Kristiansen KT, Pedersen UG, Karstensen JG, Novovic S, et al. Coronavirus disease-19 (COVID-19) associated with severe acute pancreatitis: Case report on three family members. Pancreatology. 2020; 20(4):665-7. [DOI:10.1016/j.pan.2020.04.021] [PMID] [PMCID]

[5] Banks PA, Bollen TL, Dervenis C, Gooszen HG, Johnson CD, Sarr MG, et al. Classification of acute pancreatitis-2012: revision of the Atlanta classification and definitions by international consensus. Gut. 2013; 62(1):102-11. [DOI:10.1136/ gutjnl-2012-302779] [PMID]

[6] Argiris A, Mathur-Wagh U, Wilets I, Mildvan D. Abnormalities of serum amylase and lipase in HIV-positive patients. Am J Gastroenterol. 1999; 94(5):1248-52. [DOI:10.1111/j.15720241.1999.01074.x] [PMID]

[7] Pieper-Bigelow C, Strocchi A, Levitt MD. Where does serum amylase come from and where does it go? Gastroenterol Clin North Am. 1990; 19(4):793-810. [DOI:10.1016/S08898553(21)00514-8]

[8] Berk JE, Shimamura J, Fridhandler L. Amylase changes in disorders of the lung. Gastroenterology. 1978; 74(6):1313-7. [DOI:10.1016/0016-5085(78)90714-X]

[9] de-Madaria E, Siau K, Cárdenas-Jaén K. Increased amylase and lipase in patients with COVID-19 pneumonia: Don' tblame the pancreas just yet! Gastroenterology. 2020; 160(5):1871. [DOI:10.1053/j.gastro.2020.04.044] [PMID] [PMCID]

[10] Liu F, Long X, Zhang B, Zhang W, Chen X, Zhang Z. ACE2 expression in pancreas may cause pancreatic damage after SARS-CoV-2 infection. Clin Gastroenterol Hepatol. 2020; 18(9):2128-30.e2. [DOI:10.1101/2020.02.28.20029181]

[11] Bhatia M. Inflammatory response on the pancreatic acinar cell injury. Scand J Surg. 2005; 94(2):97-102. [DOI:10.1177/145 749690509400203] [PMID]

[12] Yang J-K, Lin S-S, Ji X-J, Guo L-M. Binding of SARS coronavirus to its receptor damages islets and causes acute diabetes. Acta diabetola. 2010; 47(3):193-9. [DOI:10.1007/s00592-0090109-4] [PMID] [PMCID]

[13] Zhang H, Penninger JM, Li Y, Zhong N, Slutsky AS. Angiotensin-converting enzyme 2 (ACE2) as a SARS-CoV-2 receptor: Molecular mechanisms and potential therapeutic target. Intensive Care Med. 2020; 46(4):586-90. [DOI:10.1007/s00134020-05985-9] [PMID] [PMCID] 